\title{
Risk of tuberculosis in patients with spondyloarthritis: data from a centralized electronic database in Hong Kong
}

\author{
Natalia Chu-Oi Ciang', Shirley Chiu Wai Chan², Chak Sing Lau², Eva Tsz Fung Chiu ${ }^{2}$ and Ho Yin Chung ${ }^{2^{*}}$ (D)
}

\begin{abstract}
Background/ objective: Tuberculosis (TB) is one of the most infectious comorbidities in spondyloarthritis (SpA). Our goals were to determine the crude incidence rate of and risk factors for TB in SpA.

Method: Clinical data of 2984 patients with SpA from 11 rheumatology centres were reviewed. This included demographics, duration of follow-up, comorbidities including diabetes, chronic kidney disease, chronic heart disease, chronic lung disease, stroke and malignancies, date of diagnosis of tuberculosis, use of non-steroidal antiinflammatory drugs, duration of glucocorticoid therapy for more than 6 months, conventional (cDMARD) and biological (bDMARD) disease modifying anti-rheumatic drug therapies. Crude incidence rates were reported. Cox regression models were used to determine the risk factors for TB in patients with SpA.
\end{abstract}

Results: Forty-three patients had TB, of which 4 (9.3\%) were extra-pulmonary. The crude incidence rate of TB was 1.57 in patients with SpA, compared with 0.58 in the general population in Hong Kong. Independent risk factors identified from the multivariate Cox regression model were: alcohol use (HR 2.62; $p=0.03$ ), previous TB (HR 13.62; $p<0.001$ ), chronic lung disease (HR 3.39; $p=0.004$ ), duration of glucocorticoid therapy greater than 6 months (HR 3.25; $p=0.01$ ) and infliximab therapy (HR 5.06; $p<0.001$ ). Age was associated with decreased risk (HR 0.93; $p<0.001$ ).

Conclusion: Incidence of TB was higher in patients with SpA. Glucocorticoid therapy beyond 6 months and infliximab therapy increased the risk of TB. Rheumatologists should avoid prolonged use of glucocorticoids and consider DMAR Ds other than infliximab in the treatment of at-risk patients.

Keywords: Spondyloarthritis, Tuberculosis, Disease modifying anti-rheumatic drugs, Glucocorticoid, Infliximab

\section{Introduction}

Spondyloarthritis (SpA) is a spectrum of inflammatory rheumatic diseases comprised of ankylosing spondylitis (AS), psoriatic arthritis (PsA), enteropathic arthritis associated with inflammatory bowel disease (IBD), reactive arthritis, undifferentiated spondyloarthritis (uSpA) and human leucocyte antigen B27 (HLA-B27) associated

\footnotetext{
* Correspondence: jameschunghoyin@gmail.com

${ }^{2}$ Division of Rheumatology and Clinical Immunology, The University of Hong Kong, Hong Kong, Hong Kong

Full list of author information is available at the end of the article
}

uveitis. SpA leads to impairments in quality of life, work, leisure and daily activity [1], and is associated with many comorbidities including infection [2].

Tuberculosis (TB) is one of the most important infectious comorbidities in SpA. TB leads the global burden of morbidity and mortality, causing 1.4 million deaths annually, with the majority in Africa and Asia [3]. Previous studies have shown increased rates of TB in AS [4, 5], PsA [6] and other subtypes of SpA [7], and in patients on tumour necrosis factor inhibitor (TNFi) therapy $[8,9]$. South Korean data found more TB in AS patients on TNFi therapy, with incidence rate ratios of 4.87 compared with other drug

C C The Author(s). 2020 Open Access This article is licensed under a Creative Commons Attribution 4.0 International License, which permits use, sharing, adaptation, distribution and reproduction in any medium or format, as long as you give appropriate credit to the original author(s) and the source, provide a link to the Creative Commons licence, and indicate if changes were made. The images or other third party material in this article are included in the article's Creative Commons licence, unless indicated otherwise in a credit line to the material. If material is not included in the article's Creative Commons licence and your intended use is not permitted by statutory regulation or exceeds the permitted use, you will need to obtain permission directly from the copyright holder. To view a copy of this licence, visit http://creativecommons.org/licenses/by/4.0/. The Creative Commons Public Domain Dedication waiver (http://creativecommons.org/publicdomain/zero/1.0/) applies to the data made available in this article, unless otherwise stated in a credit line to the data. 
treatments [5], and 6.4 compared with the general population [10].

The crude incidence rate of TB in the general population in Hong Kong was 58.1 per 100,000 in 2018 [11], much higher than in western populations. TNFi therapy is known to trigger reactivation of latent TB $[12,13]$, yet conventionally used to treat SpA. Biologic drugs other than TNFi are increasingly prescribed due to lower risk of TB [14]

The Hong Kong Society of Rheumatology guidelines for screening and treatment of active and latent TB prior to starting biologics [15], though adopted by local clinicians for many years, is not foolproof in its prevention in patients with SpA [16]. The objectives of this study are to determine the crude incidence rate of and risk factors for TB in SpA.

\section{Method}

Clinic data were retrieved from the Clinical Management System (CMS) of the Hospital Authority, a centralized electronic database of medical records in all public hospitals in Hong Kong. All patients with a diagnosis of SpA were identified and reviewed by the author (HYC), a specialist in Rheumatology and Fellow of the Royal College of Physicians of Edinburgh and Hong Kong College of Physicians. These included cases of AS, PsA, IBD-associated SpA, reactive arthritis, uSpA, and HLA-B27 associated uveitis from all eleven rheumatology centers in Hong Kong (Queen Mary Hospital, Grantham Hospital, Tung Wah Hospital, Alice Ho Miu Ling Nethersole Hospital, Caritas Medical Centre, Kwong Wah Hospital, Queen Elizabeth Hospital, Pamela Youde Nethersole Eastern Hospital, Pok Oi Hospital, Prince of Wales Hospital and Tseung Kwan O Hospital). Data were collected from Feb 1994 to June 2019 by one clinician (HYC) and randomly scrutinized by another (SCWC).

Clinical data retrieved were age, sex, smoking status, alcohol use, dates of first and last follow-up, comorbidities (including diabetes, chronic kidney disease, chronic heart disease, chronic lung disease, stroke and malignancy), DMARD therapy, glucocorticoid therapy greater than 6 months, and other immunosuppressive states (chemotherapy, immunosuppressant therapy other than DMARDs, congenital and acquired immunodeficiency [including human immunodeficiency viruses [HIV] infection]). Chronic renal impairment was defined as chronic kidney disease stage 3 or above [17]. Chronic lung disease included asthma, chronic obstructive airway disease, bronchiectasis, and interstitial lung disease. Chronic heart disease included ischemic heart disease, congenital heart disease, heart failure, valvular heart disease, septal defect, and arrhythmia. Cerebrovascular accident included both ischemic and hemorrhagic stroke. Medication histories included dates of initiation and discontinuation of the following conventional diseasemodifying antirheumatic drugs (c-DMARDs): sulphasalazine, methotrexate and leflunomide; and biologic disease-modifying antirheumatic drugs (b-DMAR Ds): etanercept, infliximab, adalimumab, golimumab, certolizumab, secukinumab and ustekinumab. The primary outcome measure was the presence of new onset of TB after the diagnosis of SpA. Past history of TB was also recorded.

\section{Duration of follow-up}

Duration of follow up was defined as the time between first assessment at the rheumatology clinic and one of the following endpoints: first admission due to tuberculosis, death, last day of follow up, or end of study.

\section{DMARD therapy}

In patients with new onset TB, concurrent DMARD therapy was defined as having been prescribed within a month prior to its diagnosis. In patients without $\mathrm{TB}$, DMARD therapy was defined as having been prescribed at any time within the follow up period.

\section{Statistical analyses}

Patients with and without TB were compared using the student t-test for continuous variables and the Pearson's chi-square test for categorical variables.

Crude incidence rates of TB were described as per 1000 patient-years. Univariate Cox regression analyses were used to screen the following risk factors for TB: age [18], male gender [19], smoking [20] and alcohol use [20], diabetes mellitus (DM) [19], malignancy, chronic kidney disease, chronic lung disease, chronic heart disease, stroke, previous history of TB $[18,21]$ and other immunosuppressive states. Duration of follow-up was considered in the time variable of individual analyses. Significant independent variables with a $p$-value $<0.1$ were included in the multivariate Cox regression model using enter mode. Results were reported as $\mathrm{HR}$ and $95 \%$ confidence interval (CI). A $p$-value of less than 0.05 was defined as statistically significant. All statistics were performed using the International Business Machines Corporation Statistical Package for the Social Sciences (IBM SPSS) package 25.0. Listwise deletion was performed in the analyses (missing values not included).

\section{Results}

Out of 2969 patients with SpA in the study, 1940 (65.3\%) had AS, 642 (21.6\%) had PsA, 47 (1.6\%) had IBD-associated SpA, and $6(0.2 \%)$ had reactive arthritis. Baseline characteristics are shown in Table 1. The group of 43 patients with TB was characterized by male predominance, younger age, shorter duration of follow up, smoking and alcohol use, past history of $\mathrm{TB}$, chronic 
Table 1 Baseline characteristics of SPA patients with and without TB

\begin{tabular}{lllll}
\hline & SpA with TB & SpA without TB & P value & Total \\
\hline Chinese ethnicity & $43 / 43(100 \%)$ & $2896 / 2926(99.0 \%)$ & 0.51 & $2939 / 2969(99.0 \%)$ \\
Male sex & $36 / 43(83.7 \%)$ & $1993 / 2926(68.1 \%)$ & 0.03 & $2029 / 2969(69.3 \%)$ \\
Age (years) & $43.5 \pm 16.2$ & $49.9 \pm 14.6$ & 0.01 & $49.8 \pm 14.6$ \\
Duration of follow up (years) & $12.6 \pm 5.5$ & $9.2 \pm 5.9$ & $<0.001$ & $9.2 \pm 1.2$ \\
Radiographic sacroiliitis & $34 / 42(81.0 \%)$ & $1906 / 2784(68.5 \%)$ & 0.08 & $1305 / 1707(76.4 \%)$ \\
HLA-B27 status & $13 / 16(81.3 \%)$ & $1292 / 1691(76.4 \%)$ & 0.65 & $1940 / 2826(68.6 \%)$ \\
Smoking & $19 / 43(44.2 \%)$ & $856 / 2875(29.8 \%)$ & 0.04 & $875 / 2918(30.0 \%)$ \\
Alcohol use & $8 / 43(18.6 \%)$ & $232 / 2875(8.1 \%)$ & 0.01 & $240 / 2918(8.1 \%)$ \\
Past history of TB & $9 / 43(20.9 \%)$ & $69 / 2926(2.4 \%)$ & $<0.001$ & $78 / 2969(2.6 \%)$ \\
psoriasis & $6 / 43(14.0 \%)$ & $636 / 2926(21.7 \%)$ & 0.22 & $642 / 2969(21.6 \%)$ \\
IBD & $1 / 43(2.3 \%)$ & $46 / 2926(1.6 \%)$ & 0.69 & $47(2969)(1.6 \%)$ \\
ReA & $0 / 43(0.0 \%)$ & $6 / 2926(0.2 \%)$ & 0.77 & $6 / 2969(0.2 \%)$ \\
Diabetes Mellitus & $4 / 43(9.3 \%)$ & $265 / 2926(9.1 \%)$ & 0.96 & $269 / 2969(9.1 \%)$ \\
Chronic kidney disease & $4 / 43(9.3 \%)$ & $183 / 2926(6.3 \%)$ & 0.41 & $187 / 2969(6.3 \%)$ \\
Malignancy & $4 / 43(9.3 \%)$ & $111 / 2926(3.8 \%)$ & 0.06 & $115 / 2969(3.9 \%)$ \\
Chronic lung disease & $8 / 43(18.6 \%)$ & $90 / 2926(3.1 \%)$ & $<0.001$ & $98 / 2969(3.3 \%)$ \\
Chronic heart disease & $4 / 43(9.3 \%)$ & $190 / 2926(6.5 \%)$ & 0.46 & $194 / 2969(6.5 \%)$ \\
Cerebrovascular accident & $4 / 43(9.3 \%)$ & $99 / 2926(3.4 \%)$ & 0.04 & $103 / 2969(3.5 \%)$ \\
Other immunosuppressive states & $1 / 43(2.3 \%)$ & $56 / 2926(1.9 \%)$ & 0.85 & $57 / 2969(1.9 \%)$ \\
\hline SPA Spos &
\end{tabular}

SpA Spondyloarthritis; TB Tuberculosis; IBD Inflammatory bowel disease; ReA Reactive arthritis

Table 2 NSAID, glucocorticoid, and DMARD therapy in SpA with and without TB

\begin{tabular}{llll}
\hline & SpA with TB & SpA without TB & P value \\
\hline NSAIDs & $43 / 43(100.0 \%)$ & $2783 / 2926(95.1 \%)$ & 0.14 \\
glucocorticoid therapy $>$ months & $6 / 43(14.0 \%)$ & $148 / 2926(5.1 \%)$ & 0.01 \\
DMARDs & $29 / 43(67.4 \%)$ & $1831 / 2926(62.6 \%)$ & 0.51 \\
cDMARDs & $21 / 43(48.8 \%)$ & $1609 / 2926(55.0 \%)$ & 0.42 \\
sulfasalazine & $16 / 43(37.2 \%)$ & $1253 / 2926(42.8 \%)$ & 0.46 \\
methotrexate & $9 / 43(20.9 \%)$ & $763 / 2926(26.1 \%)$ & 0.45 \\
leflunomide & $0 / 43(0.0 \%)$ & $156 / 2926(5.3 \%)$ & 0.12 \\
bDMARDs & $17 / 43(39.5 \%)$ & $709 / 2926(24.2 \%)$ & 0.02 \\
TNFi & $17 / 43(39.5 \%)$ & $666 / 2926(22.8 \%)$ & 0.001 \\
infliximab & $10 / 43(23.3 \%)$ & $98 / 2926(3.3 \%)$ & $<0.001$ \\
etanercept & $2 / 43(4.7 \%)$ & $268 / 2926(9.2 \%)$ & 0.31 \\
adalimumab & $5 / 43(11.6 \%)$ & $235 / 2926(8.0 \%)$ & 0.39 \\
golimumab & $0 / 43(0.0 \%)$ & $196 / 2926(6.7 \%)$ & 0.08 \\
certolizumab & $0 / 43(0.0 \%)$ & $39 / 2926(1.3 \%)$ & 0.45 \\
secukinumab & $0 / 43(0.0 \%)$ & $69 / 2926(2.4 \%)$ & 0.31 \\
ustekinumab & $0 / 43(0.0 \%)$ & $19 / 2926(0.6 \%)$ & 0.60 \\
\hline N & &
\end{tabular}


lung disease, and cerebrovascular accident. More patients in this group were treated with glucocorticoid and infliximab (Table 2). No statistically significant differences were found with psoriasis, IBD, DM, chronic kidney disease, chronic heart disease and other immunosuppressive states. There was a tendency for malignancy in the group with TB (Table 1).

One case of TB was recorded before the implementation of pre-biologic therapy screening for latent TB in 2001. This case had not received any biologic therapy.

\section{Crude incidence rates of TB infection}

This cohort was characterized by long duration of follow-up, with an overall 27,308.4 patient-years in SpA. Subgroup analyses showed 18,204.2 and 9104.2 patientyears respectively for SpA on DMARDs and not on DMARDs. Crude incidence rates of $\mathrm{TB}$ in the three groups above were higher than in the general population in 2018 [11]. Results are shown in Table 3. Crude incidence rates remained high even after adjusting for age and sex (Table 3). Most of the female patients with TB had predisposing risk factors. Out of 7, 2 were smokers, 2 had a previous history of TB, 2 were on infliximab, and 3 were on long term glucocorticoid therapy.

\section{Sites of TB infection}

In the group with $\mathrm{TB}, 39$ (91\%) had pulmonary, and 4 (9.3\%) had extra-pulmonary TB. Three had TB lymphadenitis and 1 had TB meningitis (Fig. 1).

\section{Risk factors for TB}

Univariate Cox regression models screened for risk factors for TB in patients with SpA. Covariates with a $p$-value $<$ 0.10 were age (HR 0.93; $p=0.01)$, male gender (HR 2.29; $p=0.05$ ), smoking (HR 1.74; $p=0.07$ ), alcohol use (HR $2.29 ; p=0.04)$, previous history of TB (HR 6.88; $p<0.001$ ), chronic lung disease (HR 4.48; $p<0.001$ ), duration of glucocorticoid therapy greater than 6 months (HR 2.21; $p=0.03$ ), infliximab therapy (HR 5.08; $p<0.001$ ).

The multivariate Cox regression model showed that younger age, alcohol use, previous history of TB, chronic lung disease, duration of glucocorticoid therapy greater than 6 months and infliximab therapy were independent risk factors for TB in SpA. Results are shown in Table 4.

\section{Missing values}

Data on smoking and alcohol use were missing in 51 (1.7\%) patients, which was not statistically significant.

\section{Discussion}

Patients with SpA had higher crude incidence rates of TB than the general population. Risks factors included age, alcohol use, history of TB, chronic lung disease, duration of glucocorticoid therapy greater than 6 months, and infliximab therapy. The most common site of TB was pulmonary.

Age and sex adjusted crude incidence rates of TB were greater in SpA than in the general population, especially in females. Similarly elevated rates occurred regardless of DMARD therapy, suggesting that drugs were the not sole contributors to increased risk. In contrast, a Swedish study found increased risk of $\mathrm{TB}$ in biologicsexposed, compared with biologics-naïve patients with SpA (HR 7.5; 95\% CI 1.9-29) [22]. However, prevalence of TB in Asia is much higher than in Europe. The Swedish registry recorded a total of 11 cases of TB in a combined group of 38,702 patients with SpA and 200,417 persons in the general population while this study alone reported 43 cases of TB in 2984 patients with SpA. Data from this study paints a more accurate picture reflecting the endemic burden of TB in Hong Kong [11].

Table 3 Crude incidence rates of TB

\begin{tabular}{|c|c|c|c|c|}
\hline & \multicolumn{2}{|c|}{ Patients with SpA } & \multicolumn{2}{|c|}{ General population (11) } \\
\hline Patient-years & $27,308.4$ & & & \\
\hline Number of events & 43 & & & \\
\hline \multirow[t]{2}{*}{ Incidence per 1000 patient-years } & 0.64 & & 0.54 & \\
\hline & on DMARD & not on DMARD & & \\
\hline Patient-years & $18,204.2$ & 9104.2 & & \\
\hline Number of events & 29 & 14 & & \\
\hline \multirow[t]{2}{*}{ Incidence per 1000 patient-years } & 0.62 & 0.65 & 0.54 & \\
\hline & Male & Female & Male (age adjusted) & Female (age adjusted) \\
\hline Patient-years & $18,693.8$ & 8614.5 & & \\
\hline Average age & 49 & 52 & & \\
\hline Number of events & 36 & 7 & & \\
\hline Incidence per 1000 patient-years & 0.52 & 1.23 & 0.48 & 0.41 \\
\hline
\end{tabular}

TB Tuberculosis; SpA Spondyloarthritis; DMARD Disease modifying antirheumatic drug 


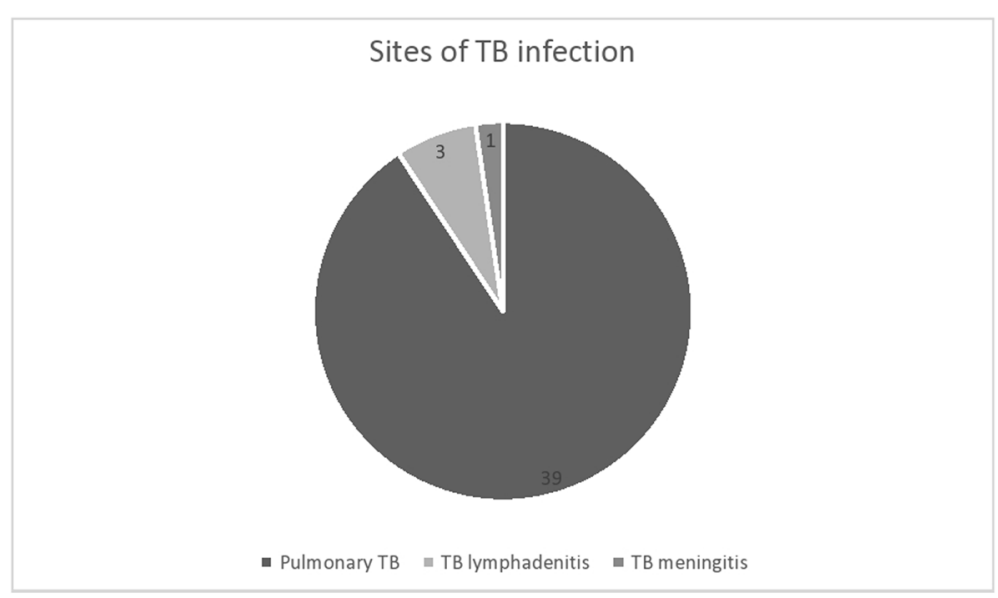

$\mathrm{TB}=$ tuberculosis

Fig. 1 Sites of TB infection

Table 4 Univariate and multivariate cox regression models of tuberculosis in SpA

\begin{tabular}{|c|c|c|c|c|}
\hline \multirow[b]{2}{*}{ Characteristic } & \multicolumn{2}{|l|}{ Univariate regression } & \multicolumn{2}{|c|}{ Multivariate logistic regression } \\
\hline & Hazard Ratio $(95 \% \mathrm{Cl})$ & $P$ value & Hazard Ratio $(95 \% \mathrm{Cl})$ & $P$ value \\
\hline Age (years) & $0.93(0.91-0.95)$ & $<0.001$ & $0.94(0.91-0.96)$ & $<0.001$ \\
\hline Male sex & $2.29(1.02-5.15)$ & 0.05 & $1.88(0.79-4.50)$ & 0.16 \\
\hline Smoking & $1.74(0.95-3.19)$ & 0.07 & $1.19(0.60-2.35)$ & 0.62 \\
\hline Alcohol use & $2.29(1.06-4.94)$ & 0.04 & $2.44(1.03-5.80)$ & 0.04 \\
\hline History of psoriasis & $0.51(0.21-1.20)$ & 0.12 & & \\
\hline History of IBD & $1.43(0.20-10.37)$ & 0.73 & & \\
\hline DM & $0.72(0.26-2.03)$ & 0.54 & & \\
\hline Past history of TB & $6.88(3.28-14.41)$ & $<0.001$ & $5.92(2.52-13.94)$ & $<0.001$ \\
\hline CKD & $0.89(0.32-2.51)$ & 0.83 & & \\
\hline CLD & $4.48(2.07-9.72)$ & $<0.001$ & $3.81(1.60-9.06)$ & 0.002 \\
\hline Malignancy & $2.07(0.74-5.80)$ & 0.17 & & \\
\hline $\mathrm{CHD}$ & $0.88(0.31-2.47)$ & 0.81 & & \\
\hline Other immunosuppressive states & $0.95(0.13-6.89)$ & 0.96 & & \\
\hline History of CVA & $1.46(0.52-4.09)$ & 0.48 & & \\
\hline Glucocorticoid therapy $>6$ months & $2.21(0.93-5.25)$ & 0.03 & $2.60(1.01-6.70)$ & 0.05 \\
\hline Sulfasalazine & $0.63(0.34-1.16)$ & 0.14 & & \\
\hline Methotrexate & $0.57(0.27-1.19)$ & 0.13 & & \\
\hline Lefluonomide & $0.05(0.00-13.72)$ & 0.29 & & \\
\hline Infliximab & $5.08(2.49-10.34)$ & $<0.001$ & $3.94(1.82-8.53)$ & $<0.001$ \\
\hline Etanercept & $0.57(0.14-2.36)$ & 0.44 & & \\
\hline Adalimumab & $1.83(0.72-4.67)$ & 0.21 & & \\
\hline Certolizumab & $0.05(0.00-32,169)$ & 0.66 & & \\
\hline Golimumab & $0.05(0.00-13.94)$ & 0.29 & & \\
\hline Secukinumab & $0.05(0.00-282.43)$ & 0.49 & & \\
\hline Ustekinumab & $0.05(0.00-657,547)$ & 0.72 & & \\
\hline
\end{tabular}


Infliximab was the only DMARD and TNFi found with significantly higher risk of TB in this study. This result is unlikely related to the pre-biologic screening policy for latent $\mathrm{TB}$ as most of the cases were recorded after its implementation in 2001 [23]. The highly variable risk profiles of individual DMARDs reflects differences in pharmacodynamic and pharmacokinetic mechanisms. TNFi deactivates $T$ cells and macrophages [24] and induces apoptosis in key immune cells [25]. Infliximab specifically has wider fluctuations in serum levels [26] and higher peak drug concentrations [27] than other TNFi. Changes in levels of TNF- $\alpha$, associated with maintenance of granuloma integrity, is correlated with disease susceptibility both in experimental models and in humans $[28,29]$. It is postulated that differential risks amongst individual TNFi is a result of differences in membrane TNF activation and the resulting effector $\mathrm{T}$ cell cascade. Infliximab and adalimumab possess at least 3 to 4 times greater risk of TB than etanercept [30]. A nation-wide South Korean study found the highest risk with infliximab (incidence rate ratio [IRR]: 6.8), followed by adalimumab (IRR: 3.5 ) and etanercept [6].

Secukinumab or ustekinumab therapy had no association with $\mathrm{TB}$, which is reassuring in this endemic region. Negligible risk in b-DMARDs with the exception of TNFi were cited in many controlled trials [31-33], national registries of biologics $[33,34]$ and postmarketing surveillance [33]. No cases of TB were found in the Psoriasis Longitudinal Assessment and Registry (PSOLAR) of 3474 patients with psoriasis and PsA given ustekinumab, over a median follow-up of 1.6 years [34], and from pooled safety analysis of 10 studies in psoriasis [33], and one study in AS [35]. Screening for latent TB have led to relatively low rates of reactivation of $\mathrm{TB}$ in AS [36]. Mandatory screening for and isoniazid treatment of latent TB prior to starting biologics reduced its occurrence in SpA [37]. Similar guidelines from the Hong Kong Society of Rheumatology have been adopted for many years [15].

Previous history of TB significantly increased the risk of TB reactivation or reinfection, with an $\mathrm{HR}$ of 13.88 (95\% CI 6.07-31.72) in our study. TB reactivation is a major health concern [38] in patients with HIV or other immunocompromised states in Western countries. However, in highly endemic regions, exposure to TB plays a more important role, while HIV takes a back seat. The prevalence of HIV in Hong Kong is negligible, with 9091 cases in a population of 7.4 million in 2017 [39], as reflected in this study in which no cases of HIV infection were reported.

Other risk factors for TB have been investigated in our cohort. While the risk of TB was no different in psoriasis as in IBD, more TB was observed in younger age groups, which could reflect a migrant population with more diverse social contacts [40]. Unsurprisingly, TB was increased in smokers and patients with chronic lung disease in our study, likely due to ventilatory restriction and impaired lung function [41], and consistent with data in TB endemic areas [42]. Alcohol use was linked to TB in this study, consistent with previous studies which found alcohol misuse contributed to additive risks in current and past smokers [43]. The link between glucocorticoid therapy and TB in our study has also been well established in a number of rheumatologic [44, 45] and non-rheumatologic conditions [46]. As long-term glucocorticoid therapy is not recommended in international consensus statements $[47,48]$, rheumatologists should be prudent in considering options for drug treatments.

Sites of TB infection may reflect the magnitude of immunosuppression, either from the disease process itself or immunosuppressive drugs. Extrapulmonary TB represents reactivation rather than nascent infection as mycobacteria from the encapsulated granuloma in the lung spread to other sites via the blood or lymphatic system [49]. In our cohort, extrapulmonary TB occurred in 4 (9.3\%) out of 43 patients with SpA, less than in RA [50], likely reflecting reduced immunosuppression from lower cumulative exposure to DMARDs. Screening and chemoprophylaxis may also have decreased TB reactivation.

\section{Limitations and future direction}

Small size of the group with TB contributed to potential bias. Limited data from subgroups of newer drugs like secukinumab and usterkinumab should be interpreted with caution. Disease activity and chronicity, which may affect the risk of TB, were not included in this study. Future studies should include prospective multinational registries to strengthen surveillance of TB [51].

\section{Conclusion}

The crude incidence rate of TB was increased in SpA when compared to the general population. Independent risk factors for $\mathrm{TB}$ were alcohol use, previous $\mathrm{TB}$, chronic lung disease, history of ischemic stroke, glucocorticoid therapy and infliximab therapy. Biologics with the exception of infliximab should be considered in SpA patients at risk for TB.

\footnotetext{
Abbreviations

TB: Tuberculosis; SpA: Spondyloarthritis; NSAID: Non-steroidal antiinflammatory drug; bDMARD: Biological disease modifying anti-rheumatic drug; CDMARD: Conventional disease modifying anti-rheumatic drug; AS: Ankylosing spondylitis; PsA: Psoriatic arthritis; IBD: Inflammatory bowel disease; uSpA: Undifferentiated spondyloarthritis; HLA: Human leukocyte antigen; TNFi: Tumor necrosis factor inhibitor; CMS: Clinical management system; DM: Diabetes mellitus; CKD: Chronic kidney disease; CLD: Chronic lung disease; CHD: Chronic heart disease; CVA: Celebrovascular disease; Cl: Confidence interval; HR: Hazard ratio; HIV: Human immunodeficiency virus; IRR: Incidence rate ratio; PSOLAR: Psoriasis longitudinal assessment and registry
} 


\section{Acknowledgements}

Not applicable.

\section{Authors' contributions}

NCOC is responsible for data analyses and manuscript preparation. SCWC is responsible for study design, data collection, and revision of manuscript. ETFC is responsible for data collection, and manuscript preparation. CSL is responsible for study design, data analyses and revision of manuscript. HYC is responsible for study design, data collection and analyses, and revision of manuscript. The author (s) read and approved the final manuscript.

\section{Funding}

None.

\section{Availability of data and materials}

Data is available from Dr. Ho Yin Chung upon reasonable request.

\section{Ethics approval and consent to participate}

The study was approved by the Institutional Review Board of the University of Hong Kong / Hospital Authority Hong Kong West Cluster (reference number UW 18-263) and local ethics committees. It was conducted in accordance with the Declaration of Helsinki and the guidance of Good Clinical Practice, November 30, 2006.

\section{Consent for publication}

Not applicable.

\section{Competing interests}

The authors declare no conflict of interest.

\section{Author details}

'Division of Rheumatology, Department of Medicine, Queen Elizabeth Hospital, Hong Kong, Hong Kong. ${ }^{2}$ Division of Rheumatology and Clinical Immunology, The University of Hong Kong, Hong Kong, Hong Kong.

Received: 29 June 2020 Accepted: 3 December 2020

Published online: 10 December 2020

\section{References}

1. Strand V, Singh JA. Patient burden of axial spondyloarthritis. J Clin Rheumatol. 2017;23:383-91.

2. Molto A, Dougados M. Comorbidities in spondyloarthritis including psoriatic arthritis. Best Pract Res Clin Rheumatol. 2018;32:390-400.

3. Organisation mondiale de la santé. Global Tuberculose Report: 2015. Genève (Suisse): Word Health Organization; 2015.

4. Carmona L, Gómez-Reino JJ, BIOBADASER group. Survival of TNF antagonists in spondylarthritis is better than in rheumatoid arthritis Data from the Spanish registry BIOBADASER. Arthritis Res Ther. 2006;8:R72.

5. Kim HW, Park JK, Yang J-A, Yoon Yl, Lee EY, Song YW, et al. Comparison of tuberculosis incidence in ankylosing spondylitis and rheumatoid arthritis during tumor necrosis factor inhibitor treatment in an intermediate burden area. Clin Rheumatol. 2014;33:1307-12.

6. Jung SM, Ju JH, Park M-S, Kwok S-K, Park K-S, Kim H-Y, et al. Risk of tuberculosis in patients treated with anti-tumor necrosis factor therapy: a nationwide study in South Korea, a country with an intermediate tuberculosis burden. Int J Rheum Dis. 2015;18:323-30.

7. Baeten D. Systematic safety follow up in a cohort of 107 patients with spondyloarthropathy treated with infliximab: a new perspective on the role of host defence in the pathogenesis of the disease? Ann Rheum Dis. 2003; 62:829-34.

8. Tubach F, Salmon D, Ravaud P, Allanore Y, Goupille P, Bréban M, et al. Risk of tuberculosis is higher with anti-tumor necrosis factor monoclonal antibody therapy than with soluble tumor necrosis factor receptor therapy: the three-year prospective french research axed on tolerance of biotherapies registry. Arthritis Rheum. 2009;60:1884-94.

9. Wallis RS, Broder MS, Wong JY, Hanson ME, Beenhouwer DO Granulomatous infectious diseases associated with tumor necrosis factor antagonists. Clin Infect Dis. 2004:38:1261-5.

10. Lee SK, Kim SY, Kim EY, Jung JY, Park MS, Kim YS, et al. Mycobacterial infections in patients treated with tumor necrosis factor antagonists in South Korea. Lung. 2013;191:565-71.
11. Centre for Health Protection. Notification \& death rate of tuberculosis (all forms). 1947-2019. https://www.chp.gov.hk/en/statistics/data/10/26/43/88. html. Accessed 7 Sept 2020.

12. Cantini F, Niccoli L, Goletti D. Adalimumab, Etanercept, infliximab, and the risk of tuberculosis: data from clinical trials, National Registries, and Postmarketing surveillance. J Rheumatol Suppl. 2014;91:47-55.

13. Minozzi S, Bonovas S, Lytras T, Pecoraro V, González-Lorenzo M, Bastiampillai AJ, et al. Risk of infections using anti-TNF agents in rheumatoid arthritis, psoriatic arthritis, and ankylosing spondylitis: a systematic review and metaanalysis. Expert Opin Drug Saf. 2016;15:11-34.

14. Cantini F, Nannini C, Niccoli L, Petrone L, Ippolito G, Goletti D. Risk of tuberculosis reactivation in patients with rheumatoid arthritis, Ankylosing spondylitis, and psoriatic arthritis receiving non-anti-TNF-targeted biologics. Mediat Inflamm. 2017;2017:1-15.

15. Hong Kong Society of Rheumatology, Mok CC, Tam LS, Chan TH, GKW L, EKM L. Management of rheumatoid arthritis: consensus recommendations from the Hong Kong Society of Rheumatology. Clin Rheumatol. 2011;30: 303-12.

16. Carmona L, Gómez-Reino JJ, Rodríguez-Valverde V, Montero D, PascualGómez E, Mola EM, et al. Effectiveness of recommendations to prevent reactivation of latent tuberculosis infection in patients treated with tumor necrosis factor antagonists. Arthritis Rheum. 2005;52:1766-72.

17. Stevens PE. Evaluation and Management of Chronic Kidney Disease: synopsis of the kidney disease: improving global outcomes 2012 clinical practice guideline. Ann Intern Med. 2013;158:825.

18. Lienhardt C. From exposure to disease: the role of environmental factors in susceptibility to and development of tuberculosis. Epidemiol Rev. 2001;23: 288-301.

19. Baker MA, Lin H-H, Chang H-Y, Murray MB. The risk of tuberculosis disease among persons with diabetes mellitus: a prospective cohort study. Clin Infect Dis. 2012;54:818-25.

20. Lin $\mathrm{H}-\mathrm{H}$, Ezzati $\mathrm{M}$, Chang $\mathrm{H}-\mathrm{Y}$, Murray $\mathrm{M}$. Association between tobacco smoking and active tuberculosis in Taiwan: prospective cohort study. Am J Respir Crit Care Med. 2009:180:475-80.

21. Keane J. TNF-blocking agents and tuberculosis: new drugs illuminate an old topic. Rheumatology. 2005:44:714-20.

22. de Vries MK, Arkema EV, Jonsson J, Bruchfeld J, Jacobsson LTH, Askling J, et al. Tuberculosis risk in Ankylosing spondylitis, other Spondyloarthritis, and psoriatic arthritis in Sweden: a population-based cohort study. Arthritis Care Res. 2018;70:1563-7.

23. Keane J, Gershon S, Wise RP, Levens EM, Schwieterman WD, Siegel JN, et al. Tuberculosis associated with infliximab, a tumor necrosis factor alphaneutralizing agent. N Engl J Med. 2001;345(15):1098-104.

24. Harris J, Keane J. How tumour necrosis factor blockers interfere with tuberculosis immunity: TNF blockers and TB immunity. Clin Exp Immunol. 2010;161:1-9.

25. Mitoma H, Horiuchi T, Tsukamoto H, Tamimoto $Y$, Kimoto $Y$, Uchino A, et al. Mechanisms for cytotoxic effects of anti-tumor necrosis factor agents on transmembrane tumor necrosis factor a-expressing cells: comparison among infliximab, etanercept, and adalimumab. Arthritis Rheum. 2008;58: 1248-57.

26. Tracey D, Klareskog L, Sasso EH, Salfeld JG, Tak PP. Tumor necrosis factor antagonist mechanisms of action: a comprehensive review. Pharmacol Ther. 2008;117:224-79.

27. St Clair EW, Wangner CL, Fasanmade AA, Wang B, Schaible T, Kavanaugh A, et al. The relationship of serum infliximab concentrations to clinical improvement in rheumatoid arthritis: results from ATTRACT, a multicenter, randomized, double-blind, placebo-controlled trial. Arthritis Rheum. 2002:46: 1451-9.

28. Flynn JL, Goldstein MM, Chan J, Triebold KJ, Pfeffer K, Lowenstein CJ, et al. Tumor necrosis factor-a is required in the protective immune response against mycobacterium tuberculosis in mice. Immunity. 1995;2:561-72.

29. Mohan VP, Scanga CA, Yu K, Scott HM, Tanaka KE, Tsang E, et al. Effects of tumor necrosis factor alpha on host immune response in chronic persistent tuberculosis: possible role for limiting pathology. Kaufmann SHE, editor. Infect Immun. 2001;69:1847-55.

30. Nacci F, Matucci-Cerinic M. Tuberculosis and other infections in the antitumour necrosis factor-alpha (anti-TNF-a) era. Best Pract Res Clin Rheumatol. 2011;25:375-88

31. Kavanaugh A, Puig L, Gottlieb AB, Ritchlin C, Li S, Wang Y, et al. Maintenance of clinical efficacy and radiographic benefit through two years 
of Ustekinumab therapy in patients with active psoriatic arthritis: results from a randomized, placebo-controlled phase III trial: Ustekinumab in PsA: 2-year results. Arthritis Care Res. 2015;67:1739-49.

32. Baeten D, Baraliakos X, Braun J, Sieper J, Emery P, van der Heijde D, et al. Anti-interleukin-17A monoclonal antibody secukinumab in treatment of ankylosing spondylitis: a randomised, double-blind, placebo-controlled trial. Lancet. 2013;382:1705-13.

33. Blauvelt A. Safety of secukinumab in the treatment of psoriasis. Expert Opin Drug Saf. 2016;15:1413-20.

34. Kalb RE, Fiorentino DF, Lebwohl MG, Toole J, Poulin Y, Cohen AD, et al. Risk of serious infection with biologic and systemic treatment of psoriasis: results from the psoriasis longitudinal assessment and registry (PSOLAR). JAMA Dermatol. 2015;151:961.

35. Baeten D, Sieper J, Braun J, Baraliakos X, Dougados M, Emery P, et al. Secukinumab, an interleukin-17A inhibitor, in Ankylosing spondylitis. N Engl J Med. 2015;373:2534-48.

36. Braun J, Baraliakos X, Listing J, Fritz C, Alten R, Burmester G, et al. Persistent clinical efficacy and safety of anti-tumour necrosis factor therapy with infliximab in patients with ankylosing spondylitis over 5 years: evidence for different types of response. Ann Rheum Dis. 2007;67:340-5.

37. Mariette X, Vencovsky J, Lortholary O, Gomez-Reino J, de Longueville M, Ralston $\mathrm{P}$, et al. The incidence of tuberculosis in patients treated with certolizumab pegol across indications: impact of baseline skin test results, more stringent screening criteria and geographic region. RMD Open. 2015; 1(1):e000044.

38. Fogel N. Tuberculosis: a disease without boundaries. Tuberculosis. 2015;95: $527-31$.

39. Centre for Health Protection. Factsheet: HIV/AIDS situation in Hong Kong. 2017. https://www.aids.gov.hk/english/surveillance/sur_report/hiv_fc2017e.pdf. Accessed 29 Jun 2020.

40. Zhu M, Han G, Takiff HE, Wang J, Ma J, Zhang M, et al. Times series analysis of age-specific tuberculosis at a rapid developing region in China, 20112016. Sci Rep. 2018:8:8727.

41. Burney P, Jithoo A, Kato B, Janson C, Mannino D, Mogilnicka EN, et al. Chronic obstructuve pulmonary disease mortality and prevalence: the associations with smoking and poverty -- a BOLD analysis. Thorax. 2014;69: 465-73.

42. Byrne AL, Marais BJ, Mitnick CD, Lecca L, Marks GB. Tuberculosis and chronic respiratory disease: a systematic review. Int J Infect Dis. 2015:32:138-46.

43. Thomas BE, Thiruvengadam K, S R, Kadam D, Ovung S, Sivakumar S, et al. Smoking, alcohol use disorder and tuberculosis treatment outcomes: A dual co-morbidity burden that cannot be ignored. PLoS One. 2019;14:e0220507.

44. Greenberg JD, Reed G, Kremer JM, Tindall E, Kavanaugh A, Zheng C, et al. Association of methotrexate and tumour necrosis factor antagonists with risk of infectious outcomes including opportunistic infections in the CORRONA registry. Ann Rheum Dis. 2010;69:380-6.

45. Noel V, Lortholary O, Casassus P, Cohen P, Genereau T, Andre MH, et al. Risk factors and prognostic influence of infection in a single cohort of 87 adults with systemic lupus erythematosus. Ann Rheum Dis. 2001;60:1141-4.

46. Jick SS, Lieberman ES, Rahman MU, Choi HK. Glucocorticoid use, other associated factors, and the risk of tuberculosis. Arthritis Rheum. 2006;55:19-26.

47. Tam LS, Wei JC, Aggarwal A, Baek HJ, Cheung PP, Chiowchanwisawakit P, et al. 2018 APLAR axial spondyloarthritis treatment recommendations. Int J Rhuem Dis. 2019;22:340-156.

48. Van der Heijde D, Ramiro S, Landewe R, Baraliakos X, Van den Bosch F, Sepriano A, et al. 2016 update of the ASAS-EULAR management recommendations for axial spondyloarthritis. Ann Rheum Dis. 2017;76:978-91.

49. Golden MP, Virkram HR. Extrapulmonary tuberculosis: an overview. Am Fam Physician. 2005;72:1761-8.

50. Chung $T$, Ko HJ, Lau CS, Chung HY. A retrospective study on the risk of tuberculosis in patients with rheumatoid arthritis. Rheumatol Int. 2020;40: 983-90.

51. Scrivo R, Armignacco O. Tuberculosis risk and anti-tumour necrosis factor agents in rheumatoid arthritis: a critical appraisal of national registry data. Int J Rheum Dis. 2014;17:716-24.

\section{Publisher's Note}

Springer Nature remains neutral with regard to jurisdictional claims in published maps and institutional affiliations.

\section{Ready to submit your research? Choose BMC and benefit from:}

- fast, convenient online submission

- thorough peer review by experienced researchers in your field

- rapid publication on acceptance

- support for research data, including large and complex data types

- gold Open Access which fosters wider collaboration and increased citations

- maximum visibility for your research: over $100 \mathrm{M}$ website views per year

At BMC, research is always in progress.

Learn more biomedcentral.com/submissions 